\title{
INDAHNYA BETAWI
}

\author{
Mita Purbasari \\ Jurusan Desain Komunikasi Visual, Fakultas Komunikasi dan Multimedia, Universitas Bina Nusantara \\ Jln. K.H. Syahdan No. 9, Palmerah, Jakarta Barat 11480 \\ mitawahid@binus.edu
}

\begin{abstract}
Frequently the uniqueness of Betawi with its superiority and shortage performance attracts many people. This article clarifies beauty in Betawi's modest ethnic which concerns on history, artefact, culture, art, cloth and clothes' motif, food, and ceremony relates to people's life, by using cultural study method and structuralism theory. It is concluded that Betawi culture has been created through a long process, even though in fact they have been removed now, but the assimilation process with various ethnics in Indonesia makes Betawi ethnic is exist and recognized. Various arts together with cultural acculturation, language, and people arise multiple perceptions toward Betawi ethnic. The modesty factor causes Betawi ethnic can be accepted by all social levels in Indonesia. With cultural richness of Betawi, so that preservation on this culture is needed, considering on the Betawi's characteristic which is less aware of their existence.
\end{abstract}

Keywords: Betawi ethnic, culture, acculturation

\begin{abstract}
ABSTRAK
Keunikan Betawi dengan segala kekurangan dan kelebihannya seringkali membuat orang terkesima. Artikel ini menjelaskan keindahan di dalam kesederhanaan etnik Betawi dengan bahasan tentang sejarah, artefak, budaya, kesenian, motif kain dan pakaian, makanan, dan upacara terkait dengan kehidupan manusia dengan metode studi kultur dan teori strukturalisme. Disimpulkan bahwa kebudayaan Betawi telah terbentuk melalui proses yang panjang, walaupun pada kenyataannya mereka sekarang tergusur, tetapi proses asimilasi dengan berbagai suku di Indonesia yang membuat suku Betawi tetap ada dan diakui. Ragam kesenian beserta dengan akulturasi budaya, bahasa, dan manusia menimbulkan berbagai persepsi terhadap etnik Betawi. Faktor kesederhanaan membuat etnik Betawi diterima di segala lapisan masyarakat Indonesia. Dengan kekayaan budaya yang dimiliki oleh masyarakat Betawi, maka perlu adanya pelestarian terhadap kebudayaan ini, mengingat sifat masyarakatnya yang kurang peduli akan keberadaannya sendiri.
\end{abstract}

Kata kunci: etnik Betawi, kebudayaan, akulturasi 


\section{PENDAHULUAN}

Jakarta memang unik karena tidak bisa sekedar mewakili etnis penduduk aslinya, yaitu Betawi, tetapi juga menjadi rumah bagi berbagai manusia, suku, budaya, dan etnis lain yang datang, hidup, dan berkembang di dalamnya. Masih banyak perdebatan yang menganggap suku Betawi bukan merupakan penduduk asli Jakarta.

Betawi adalah sebuah etnik dengan jumlah penduduk yang mendominasi Jakarta. Orang Betawi telah ada jauh sebelum Jan Pieterzoon Coen membakar Jayakarta pada tahun 1619 dan mendirikan di atas reruntuhan tersebut sebuah kota bernama Batavia. Artinya, jauh sebelum menjadi ibu kota negara, sekelompok besar orang telah mendiami kota Jakarta. Bahkan, menurut sejarahwan Sagiman MD, penduduk Betawi telah mendiami Jakarta sekitar sejak zaman batu baru atau Neoliticum, yaitu 1500 SM. Dari masa ke masa, masyarakat Betawi terus berkembang dengan cirri budaya yang makin lama semakin mantap sehingga mudah dibedakan dengan kelompok etnis lain.

Betawi merupakan etnis yang kaya akan keragaman budaya, bahasa, dan kultur. Warna-warni ini membawa aneka persepsi, tafsiran, dan pemahaman tentang Betawi, baik dari segi penduduk asli, kultur, maupun kebudayaan. Bahkan, ada yang berpendapat bahwa penduduk Betawi itu majemuk. Artinya, mereka berasal dari percampuran darah berbagai suku bangsa dan bangsa asing.

Beberapa penelitian tentang masyarakat Betawi mengatakan bahwa kebudayaan Betawi sarat akan pengaruh dari Belanda, Cina, Arab, India, Portugis, dan Sunda. Dikatakan pula bahwa baju pengantin Betawi yang berwarna merah mengadopsi budaya Cina, sedangkan yang hijau mendapat pengaruh Islam (Arab). Sepintas, kata-kata dalam dialek Betawi berkesan dialek Tionghoa, tapi bila diteliti lebih lanjut, maka banyak terdapat bahasa Belanda dan Arab yang diIndonesiakan.

Di luar sana, terdapat berbagai ragam pendapat dan pandangan tentang masyarakat Betawi, mulai dari yang positif sampai dengan yang negatif. Ada pendapat yang mengatakan bahwa Betawi bukanlah suatu suku bangsa, akan tetapi hanya berupa komunitas dari beragam akulturasi suku bangsa dan bangsa asing. Dengan kata lain, orang Betawi adalah masyarakat yang majemuk, yang berasal dari percampuran darah berbagai suku bangsa dan bangsa-bangsa asing (Shahab, 2008). Pendapat serupa berasal dari Yahya Andi Saputra, seorang pengamat etnik Betawi.

Kemilau dan kekayaan budaya Betawi mendorong penulis untuk mencari tahu lebih banyak informasi tentang Betawi, baik dalam hal sejarah, penduduk, kesenian, dan kultur keseharian mereka. Penulis tidak akan menyimpulkan suatu keputusan karena paparan ini hanya bersifat menambah wawasan, dengan sedikit cerita tentang Betawi. Diharapkan, para pembaca dapat lebih mengenal, memahami, dan mengerti masyarakat Betawi dengan segala kelebihan dan kekurangan mereka.

Konon, lahirnya masyarakat yang sekarang ini bermukim di kota Jakarta diperkirakan sudah mulai ada sejak 1500 tahun sebelum Masehi. Hal ini dapat dilihat dari temuan arkeologis berupa sebagai berikut. Pertama, artefak. Pecahan gerabah berupa alat dapur/makan; alat berburu seperti kapak persegi, beliung, dan serpihan batu; perhiasan seperti 'mute' dan gelang batu; serta alat bercocok tanam dari batu. Kedua, dalam Prasasti Tugu dikatakan bahwa pada pertengahan abad ke-5 M, sudah mengenal agama Hindu dengan bentuk kerajaan Indonesia-Hindu, yaitu Tarumanegara (Raja Purnawarman), yang meliputi Jakarta, Bekasi sampai Citarum, Bogor, dan Banten.

Dengan temuan yang ada, dapat diambil simpulan bahwa kehidupan etnis Betawi pada masa prasejarah dapat dikatakan sudah mengenal tempat tinggal yang tetap, tahu bagaimana membangun rumah, tahu bercocok tanam, tahu berorganisasi, mengenal perdagangan dengan sistem barter, ilmu perbintangan dan pelayaran, cara membuat pakaian, memasak, dan beternak. Pendek kata, masyarakat Betawi kuno sudah memiliki kebudayaan yang tinggi sebelum kehadiran orang Eropa. 
Berdasarkan ciri kebudayaan, etnik Betawi dibagi mejadi dua, yaitu Betawi Tengah (Betawi Kota) dan Betawi Pinggiran, yang pada masa pemerintahan Hindia Belanda disebut Betawi Ora. Berdasarkan geografis, etnik Betawi dibagi menjadi Betawi Tengah (Kota), Betawi Pesisir, dan Betawi Pinggir (Udik/Ora).

Betawi Tengah/Kota menetap di bagian kota Jakarta yang dahulu dinamakan keresidenan Batavia (Jakarta Pusat - urban), mendapat pengaruh kuat kebudayaan Melayu (Islam). Betawi Tengah menganut gaya hidup tempo lama, misalnya perayaan upacara perkawinan, khitanan, tradisi lebaran, dan memegang teguh agama serta adat istiadat (mengaji). Orang Betawi yang tinggal di Jakarta Pusat mengalami tingkat arus urbanisasi dan modernisasi dalam skala paling tinggi, juga mengalami tingkat kawin campuran paling tinggi. Dalam bidang kesenian, mereka menikmati keroncong Tugu, musik Gambus, Qasidah, orkes Rebana, dan menggemari cerita bernafaskan Islam seperti cerita Seribu Satu Malam. Mereka memiliki dialek yang disebut dialek Betawi Kota, bervokal akhiran $e$ pada beberapa kata yang dalam bahasa Indonesia berupa $a$ atau $a h$, misalnya: kenapa menjadi kenape.

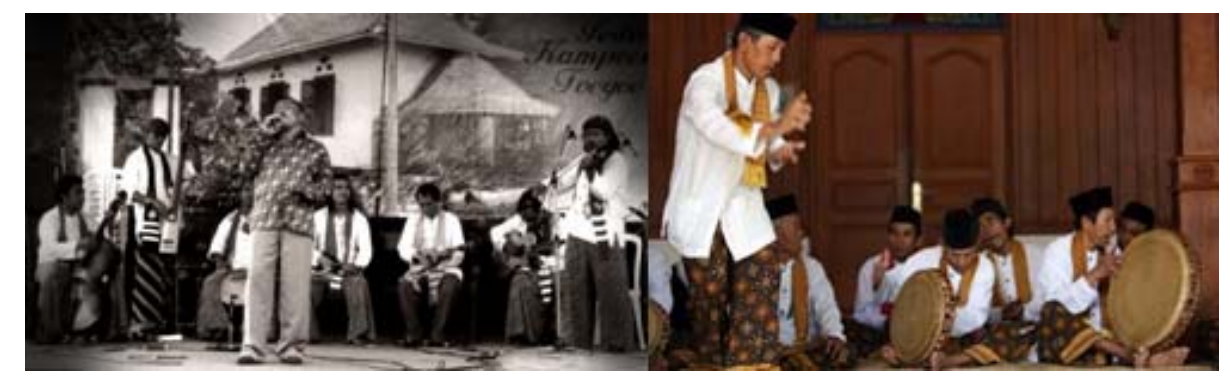

Gambar 1 Keroncong Tugu

Gambar 2 Orkes Rebana

Betawi Pinggiran, biasa disebut Betawi Udik atau Ora, terdiri atas dua kelompok, yaitu pertama, kelompok dari bagian Utara dan Barat Jakarta serta Tangerang, yang dipengaruhi oleh kebudayaan Cina; kedua, kelompok dari bagian Timur dan Selatan Jakarta, Bekasi, dan Bogor, yang dipengaruhi oleh kebudayaan dan adat istiadat Sunda.

Umumnya, Betawi Pinggiran berasal dari ekonomi kelas bawah, bertumpu pada bidang pertanian, dan bertaraf pendidikan rendah. Pada perkembangannya, masyarakat Betawi Pinggiran mengalami perubahan pola pekerjaan dan pendidikan yang lebih baik. Dalam bidang kesenian, yang dihasilkan adalah Gambang Kromong, Lenong, Wayang Topeng, dan lainnya. Mereka menyenangi cerita seperti Sam Kok dan Tiga Negeri (pengaruh Tionghoa). Dialek Betawi Pinggiran tidak terdapat perubahan vokal a menjadi e, misalnya: kenapa menjadi ngapa. Keberadaan dua kebudayaan ini disebabkan oleh banyak aspek, meliputi perbedaan latar belakang sejarah, ekonomi, sosiologi, dan aspek etnis, misalnya keaslian dari suku yang mempengaruhi kebudayaan mereka.

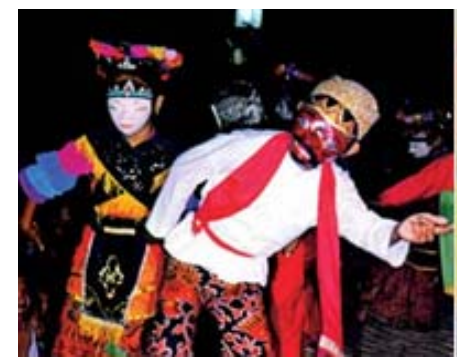

Gambar 3 Topeng Betawi

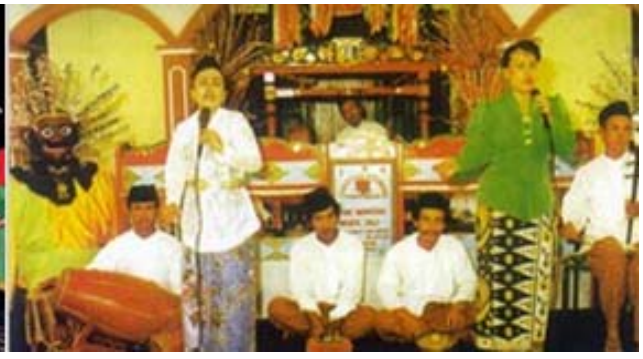

Gambar 4 Gambang Kromong 
Bagi masyarakat Betawi sendiri, segala yang tumbuh dan berkembang di tengah kehidupan budaya dirasakan sebagai miliknya sendiri seutuhnya, tanpa mempermasalahkan dari mana asal unsur yang telah membentuk kebudayaan itu. Demikian pula, sikapnya terhadap kesenian mereka sebagai salah satu unsur kebudayaan yang paling kuat mengungkapkan ciri-ciri keBetawiannya, terutama pada seni pertunjukan, disamping bahasa.

Secara garis besar, kebudayaan dan kesenian etnis Betawi tumbuh dan berkembang di kalangan rakyat secara spontan dengan segala kesederhanaannya. Oleh sebab itu, kesenian Betawi dapat digolongkan sebagai kesenian rakyat. Keberadaban masyarakat Betawi sebagai suku bangsa bisa disimak dari pengakuan mereka terhadap ciri-ciri budaya tertentu seperti bahasa, dialek, dan kesenian. Tiga yang dianggap penting dalam fase kehidupan orang Betawi, yaitu khitanan, kawinan, dan kematian. Adat hidup yang banyak bertopang pada agama Islam lebih mengajarkan mereka untuk lebih mengingat-ingat hari kematian. Ini merupakan ritual yang sarat akan unsur agamis.

Budaya khitanan selalu dirayakan dengan meriah dan semarak oleh masyarakat Betawi. Khitanan alias sunat bagi orang Betawi adalah upacara memotong penis anak laki yang memasuki akil balik dalam ukuran tertentu. Menurut budaya Betawi, jika anak lelaki sulung sudah akil balig belum disunat, maka shalatnya tidak sah. Seorang anak yang sudah menjadi "sempurna" mempunyai kewajiban melakukan ibadah dan memahami peraturan adat yang berlaku. Dengan kata lain, bagi masyarakat Betawi, sunat diartikan sebagai pembeda antara anak-anak dengan manusia dewasa.

Anak lelaki yang akan disunat disebut dengan nama penganten sunat. Seperti layaknya seorang penganten Betawi, anak ini mendapat perlakuan istimewa, yaitu sang anak dikenai pakaian lengkap (sadariah) dan diarak berkeliling kampung sambil mengendarai kuda hias, didampingi iringan delman hias berisikan teman bermain yang sebaya. Kemeriahan acara khitanan juga dapat ditemui dari semaraknya musik rebana ketimpring, yang disertai dengan shalawat dustur dan badar. Tidak lupa, iringan penganten sunat juga diikuti oleh rombongan tetangga dan orang kampung. Hidangan utama khitanan biasanya nasi kuning, serondeng, bawang goreng, dan emping ninjo. Boneka raksasa berisikan manusia hasil akulturasi budaya India (Hindu) dan ondel-ondel juga beraksi dalam upacara ini. Tontonan lenong, topeng, Sohibul hikayat, dan wayang kulit menjadi hal yang ditunggu-tunggu semua undangan sehingga menjadi ramai dan sangat meriah.

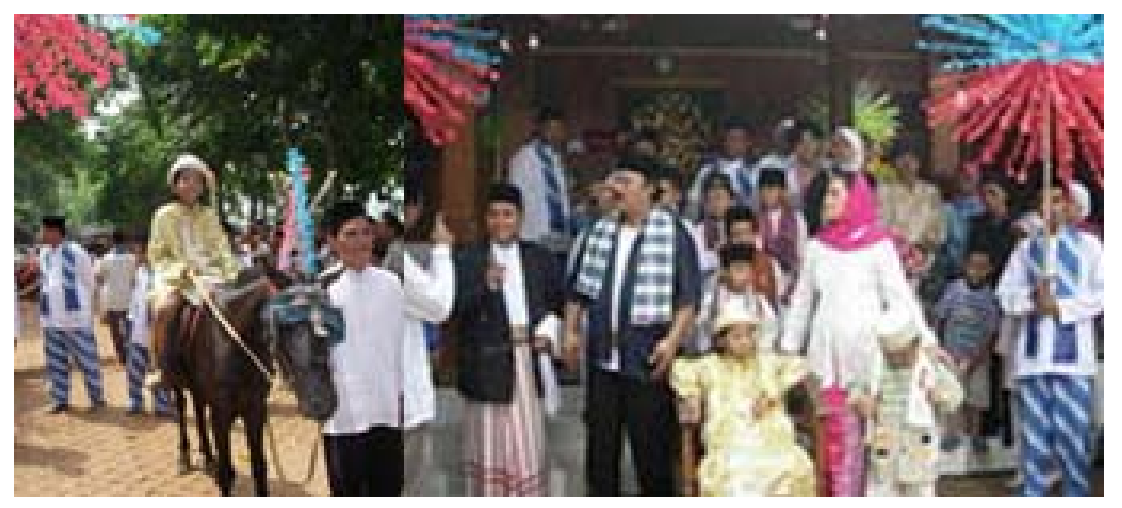

Gambar 5 Penganten Sunat Betawi

Ritual sakral selanjutnya yang dialami oleh masyarakat Betawi saat memasuki kehidupan dewasa adalah pernikahan. Upacara perkawinan dalam masyarakat Betawi merupakan salah satu siklus kehidupan yang sangat penting. Upacara itu sendiri diartikan sebagai tingkah laku resmi yang dibakukan untuk menandai peristiwa yang tidak ditujukan pada kegiatan teknis sehari-hari, tetapi mempunyai kaitan dengan kepercayaan di luar kekuasaan manusia. Oleh karena itu, dalam setiap 
upacara perkawinan, kedua mempelai ditampilkan secara istimewa, dilengkapi dengan tata rias wajah, sanggul serta tata rias busana lengkap, sesuai dengan dengan kelengkapan adat istiadat sebelum dan sesudah perkawinan.

Tujuan perkawinan tersebut, menurut masyarakat dan budaya Betawi adalah memenuhi kewajiban mulia yang diwajibkan kepada setiap warga masyarakat yang sudah dewasa dan memenuhi syarat untuk itu. Orang Betawi yang mayoritas beragama Islam yakin bahwa perkawinan adalah salah satu sunnah bagi umat sehingga dipandang sebagai suatu perintah agama untuk melengkapi norma kehidupan manusia sebagai mahluk sosial dan ciptan Tuhan yang Maha Mulia.

Sistem perkawinan pada masyarakat Betawi pada dasarnya mengikuti hukum Islam, kepada siapa mereka boleh atau dilarang mengadakan hubungan perkawinan. Dalam mencari jodoh, baik pemuda maupun pemudi bebas memilih teman hidup mereka. Namun demikian, persetujuan orang tua kedua belah pihak sangat penting karena orang tualah yang akan membantu terlaksananya perkawinan tersebut.

Pernikahan dalam adat Betawi memiliki keunikan tersendiri. Dalam budaya asli, pernikahan Betawi memiliki tahapan beragam, mulai dari lamaran, pertunangan, seserahan, sampai pernikahan. Pada hari yang ditunggu-tunggu, calon mempelai pria datang beriring-iringan diantar sanak saudara menuju rumah mempelai wanita. Zaman sekarang, biasanya ijab dan kabul dilaksanakan di rumah mempelai wanita. Hal menarik dalam adat pernikahan Betawi adalah prosesi penyambutan oleh mempelai wanita selaku tuan rumah. Petasan dan musik rebana disiapkan untuk menyambut sang 'tamu agung'. Begitu mempelai pria bersama keluarga tiba, petasan rentet dinyalakan bersamaan dengan musik rebana yang menyanyikan lagu shalawatan. Ketika datang, mempelai pria tetap membawa aneka makanan khas Betawi seperti buah-buahan dan roti buaya. Roti buaya merupakan simbol kesetiaan. Dengan demikian, diharapkan sang pengantin saling setia seperti buaya yang hanya kawin sekali seumur hidup.

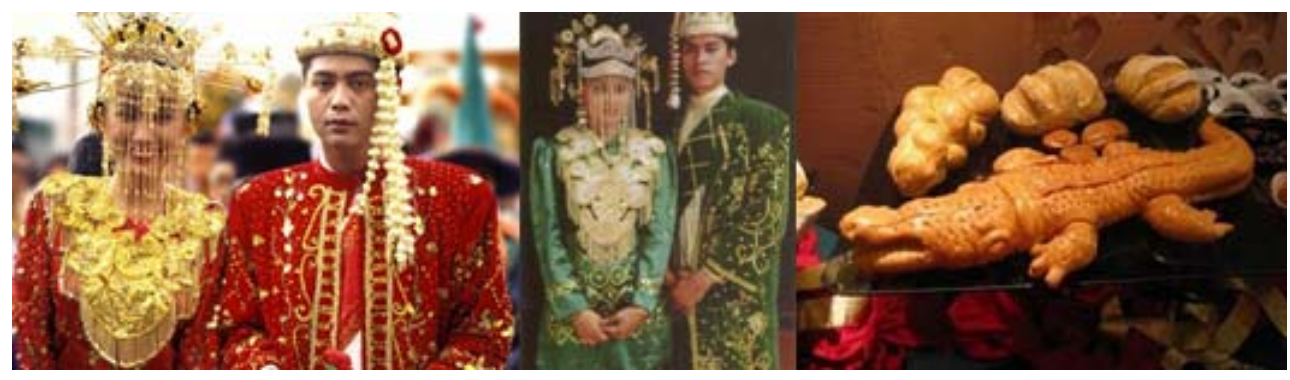

Gambar 6 Penganten Betawi (Pengaruh Tionghoa \& Arab)

Gambar 7 Roti Buaya

Lain halnya dengan ritual sakral khitanan dan perkawinan, ritual kematian tidak dirayakan secara semarak dan meriah. Barangkali karena sifat ritual sakral kematian ini lebih banyak berhubungan dengan Yang Maha Kuasa, Sang Khaliq, maka ritual dilakukan secara khusuk dan hikmat. Tradisi di daerah Betawi berbeda dengan di tempat lain. Apabila seseorang meninggal, keluarga menyelenggarakan pembacaan Al-Quran yang lamanya bergantung pada usia yang meninggal dan kelas ekonomi keluarga yang meninggal. Apabila ekonomi keluarga yang meninggal termasuk kelas menengah ke atas, maka pembacaan ayat suci Al-Quran dilakukan selama tujuh hari tujuh malam, dan biasanya dilaksanakan di makam. Ada pula yang lebih dari itu, terutama jika keluarga yang meninggal termasuk keluarga yang terhormat, maka pembacaan Al-Quran dilaksanakan selama empat puluh hari empat puluh malam. Peristiwa ini sudah jarang sekali kita temui sekarang ini. 
Kesenian wayang Betawi nyaris tidak ada yang mengetahui keberadaannya, bahkan bisa dibilang hampir punah. Wayang Betawi memang sudah sangat jarang digelar seperti wayang kulit atau wayang golek. Sebenarnya, wayang Betawi hampir mirip dengan wayang kulit dari Jawa Tengah, baik jenis wayang, tokoh, maupun jalan ceritanya tidak berbeda dengan wayang kulit. Jika diperhatikan secara detil, bentuk gapit atau pegangan wayang pada wayang kulit Betawi tidak memakai bahan tanduk, melainkan menggunakan rotan. Warna cerah mendominasi wayang kulit Betawi.Penampilan wayang sederhana sehingga menepikan aspek estetika, moral, dan falsafah.Bedanyalagi, sang dalang menuturkan cerita dalam bahasa Indonesia dialek Betawi dan sedikit bahasa Sunda, pendek kata menggunakan bahasa Indonesia pergaulan agar mudah dipahami segala lapisan masyarakat dari berbagai suku. Cerita yang dimainkan berupa cerita lucu dan seru, ada perang dan kaya akan gurauan. Selama ini wayang kulit Betawi hanya dimainkan di daerah pinggiran, yaitu tempat asal tumbuhnya wayang kulit ini.

Betawi memang kaya budaya seperti kuliner, musik, tari, teater, seni, pakaian, kerajinan tangan, sampai upacara. Walaupun kebudayaan itu sudah mulai kalah kehadirannya dengan kebudayaan modern, namun kebudayan betawi tetap memiliki penggemar dan penikmat tersendiri. Tidak kalah dengan daerah lain di Indonesia, Betawi juga memiliki kerajinan batik sebagai salah satu dari seni tekstil Betawi. Tekstil Betawi terkenal akan nuansa warna dan ragam, dengan ciri khas nuansa kesenian Betawi yang dipengaruhi oleh budaya Cina, Timur Tengah, dan Eropa. Hal ini terjadi karena begitu banyak akulturasi dari berbagai kebudayaan asing dan lokal yang terjadi di Betawi.

Motif Buketan, Liong, dan Lokcan atau Burung Hong terdapat pada batik Betawi pengaruh Cina. Sementara itu, motif kereta kuda dan binatang khas Eropa dengan warna biru menandakan adanya pengaruh Eropa. Pengaruh Timur Tengah dapat dilihat dari kebaya encim, kebayak enyak, baju sadariah, baju abang none, dan baju pengantin Betawi. Batik Betawi juga memiliki motif lain seperti Ondel-ondel (boneka tolak bala), Nusa Kelapa (sebutan leluhur Betawi untuk Jakarta), Ciliwung (peradaban manusia berasal dari tepian Sungai Ciliwung, motif ini sebagai simbol rejeki yang terus mengalir bak sebuah aliran kali), Rasamala (sebutan untuk pohon Jati Hindia yang kulit kayunya mengeluarkan bau wangi, kini merupakan pohon langka dan hanya terdapat di Kebon Raya Bogor), dan Salakanegara (merupakan batik kerajaan pertama di tanah Betawi yang didirikan oleh Aki Tirem 130 Masehi, berkaitan dengan kepercayaan yang menganggap Gunung Salak mempunyai kekuatan).

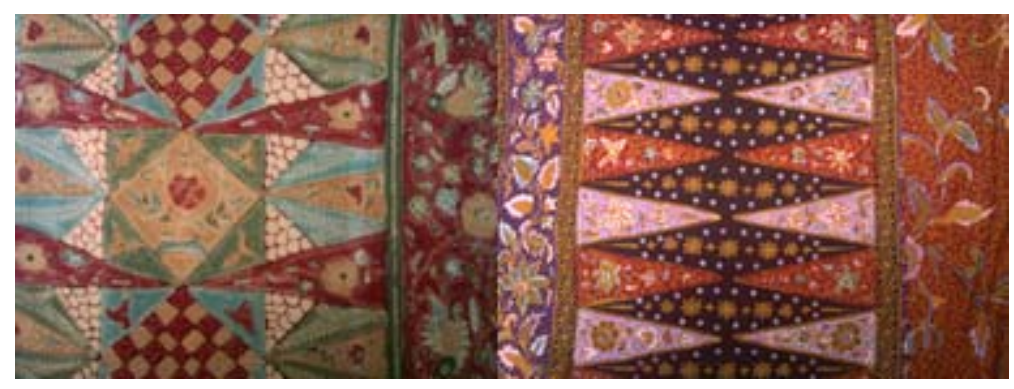

Gambar 8 Batik Betawi (Eropa)

Gambar 9 Batik Betawi 


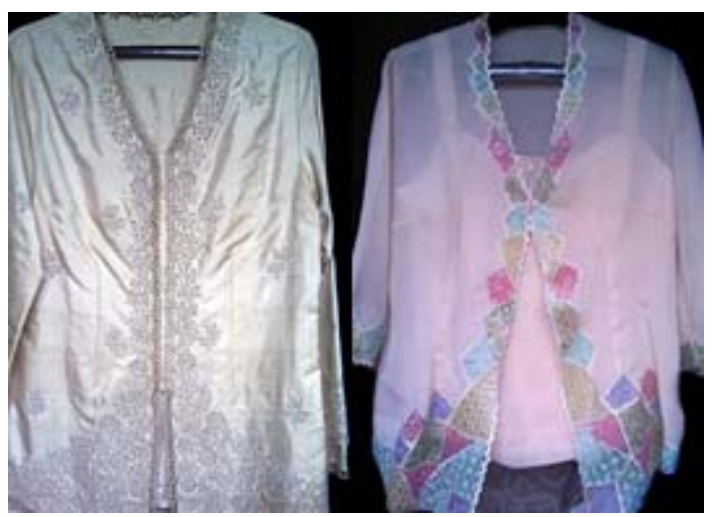

Gambar 10 Kebaya Encim

Selain kesenian dan objek wisata yang luar biasa, masyarakat Betawi juga memiliki wisata kuliner yang lezat, baik makanan pembuka, utama, maupun jajanan pasar. Seperti halnya kesenian Betawi, kuliner Betawi yang unik mendapat pengaruh dari bangsa Arab, Portugis, India, Cina, dan Belanda. Gaya kuliner Betawi sangat beragam, berbeda lokasi sudah ada sentuhan rasa yang berbeda, misalnya Laksa dan Soto Betawi. Umumnya Laksa Betawi berkuah kuning, sedangkan kuah Soto Betawi beragam, ada yang berkuah santan putih kekuningan tanpa potongan tomat dan kentang goreng; berkuah kemerahan dengan isi komplot, ada emping, tomat, dan kentang goreng.

Sayur Asem Betawi cukup terkenal. Uniknya sayur asem ini berisi jengkol dan petai. Pecak Gurame, Ketoprak, Asinan, dan Nasi Uduk juga menghiasi jajaran makanan tradisional khas Betawi. Satu nama sayur khas betawi yang cukup aneh didengar dan langka adalah sayur Babanci. Bisa dibilang jenis makanan ini hampir punah karena bahan sayur sudah sulit ditemukan di Jakarta seperti temu mangga, kedaung, bangle, adas, dan lempuyang. Sayur Babanci bumbunya banyak sekali, rasanya bukan seperti soto, bukan gule, dan bukan kare sehingga karena rasanya campur-campur dan tidak jelas seperti banci, maka disebut Sayur Babanci.

Beberapa makanan langka Betawi yang lain adalah Bubur Ase (bubur ayam dengan asinan sawi dan kuah semur), Sayur Gabus Pucung, Es Selendang Mayang, dan Nasi Ulam (mendapat pengaruh Timur Tengah).

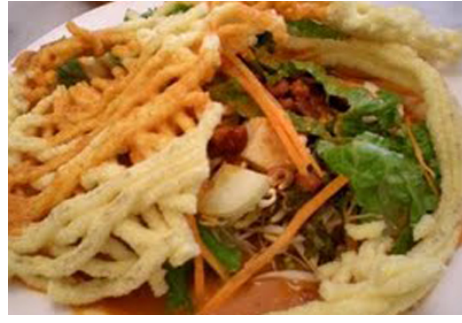

Gambar 11 Asinan Betawi

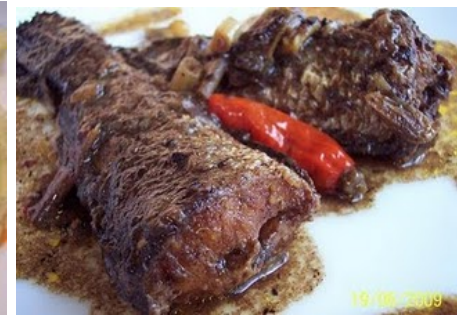

Gambar 12 Sayur Gabus Pucung

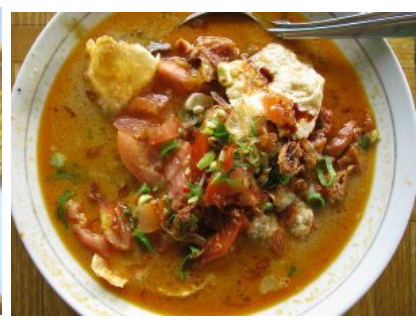

Gambar 13 Soto Betawi 


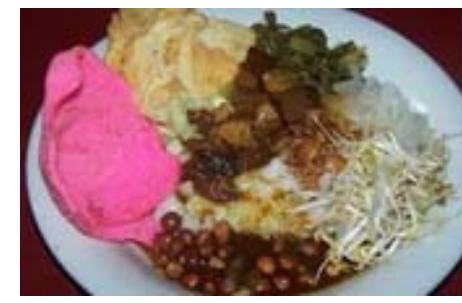

Gambar 14 Bubur Ase

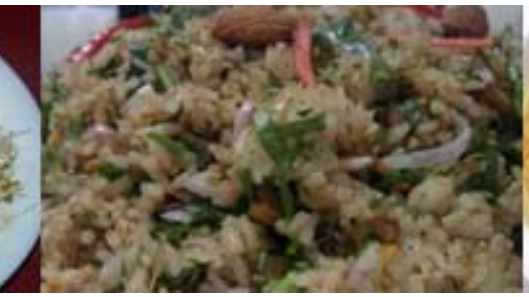

Gambar 15 Nasi Ulam

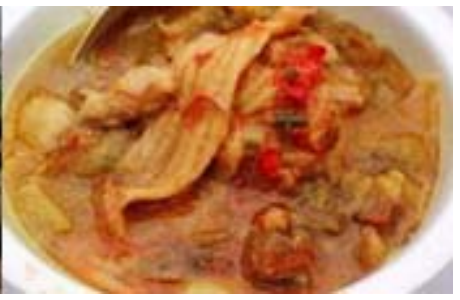

Gambar 16 Sayur Babanci

Jajanan pasar Betawi memiliki keunikan sendiri, yaitu selain rasanya yang manis, warnanya pun juga sangat khas. Beberapa contoh jajanan pasar khas Betawi adalah kue rangi, kue pancong, kue cucur, kerak telor, kue mangkok, kue ape, kue putu mayang, kue putu ayu, kue ku (mendapat pengaruh Cina), kue putu yang berwarna hijau dengan isi gula merah, kue gemblong, es doger, dan es putar.

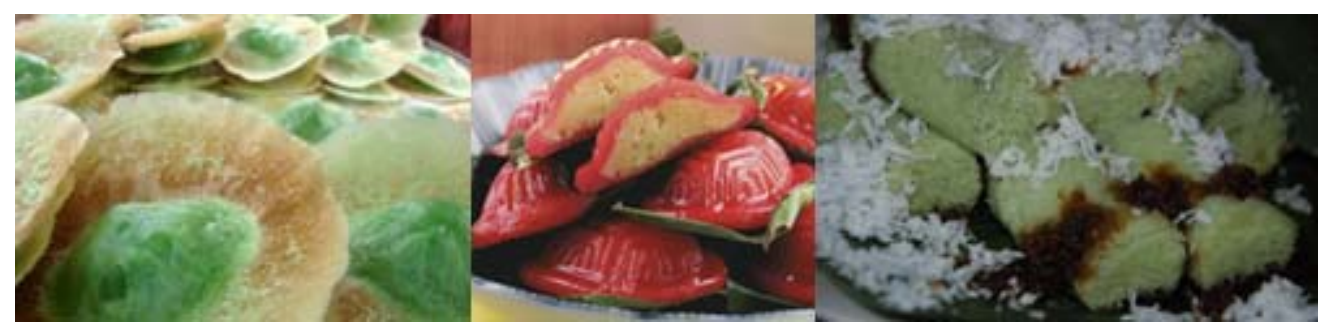

Gambar 17 Kue Ape $\quad$ Gambar 18 Kue Ku Gambar 19 Kue Putu

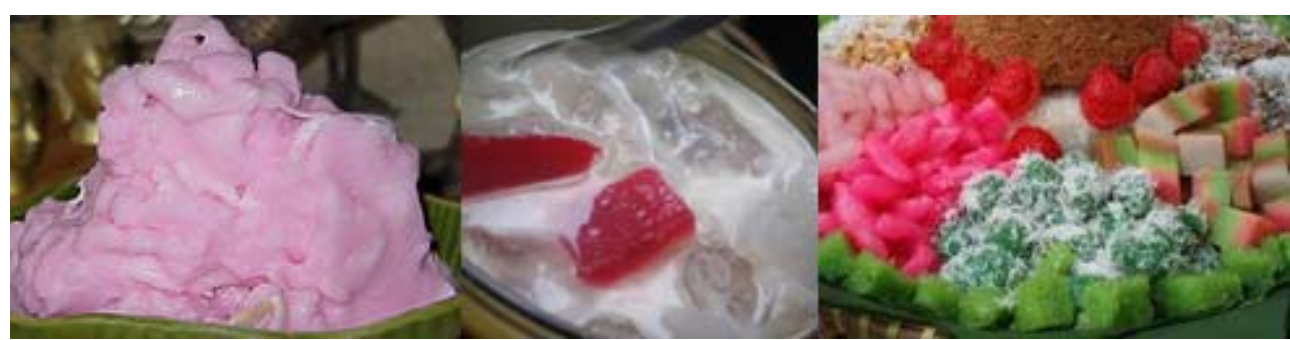

Gambar 20 Es Doger

Gambar 21 Es

Selendang Mayang
Gambar 22 Cemilan

Khas Betawi

\section{METODE PENELITIAN}

Penulisan menggunakan pendekatan studi kultur dan berdasarkan teori strukturalisme. Penulis mengumpulkan semua data yang berhubungan dengan Betawi, baik dalam hal budaya, kesenian, tingkah laku, sejarah, dan lainnya. Dengan adanya data ini, maka diharapkan kita dapat melihat keadaan objek secara lebih jelas, menyingkapi sifat instrinsiknya yang tidak terikat oleh waktu, dan penetapan hubungan antara fakta atau unsur sistem tersebut. Diharapkan, metode ini dapat menyingkap dan melukiskan struktur inti dari masyarakat Betawi. 


\section{HASIL DAN PEMBAHASAN}

Kebudayaan Betawi bukan merupakan kebudayaan kemarin sore, keragaman dan keunikan budaya membuktikan bahwa masyarakat Betawi memiliki tingkat kehidupan yang tinggi.

Dengan temuan arkeologis berupa artefak dan peninggalan prasasti, maka dapat diperkirakan bahwa sejak zaman prasejarah, masyarakat Betawi sudah mengenal tempat tinggal yang tetap, tahu bagaimana membangun rumah, tahu bercocok tanam di tanah darat, tahu berorganisasi dengan cara memilih pemimpin dari antara para anggota suku, mengenal perdagangan sistem barter, ilmu perbintangan dan pelayaran, dan memasak. Pendek kata, menurut data sejarah, masyarakat Betawi kuno sudah memiliki kebudayaan tinggi sebelum kehadiran orang Eropa.

Moto hidup orang Betawi yang ingin senang terus, membuat mereka tidak ambil pusing soal polemik asal muasal itu. Orang Betawi polos dan jenaka. Bagi mereka kualitas manusia itu tidak ditentukan oleh kapan lahir dan dari keturunan siapa, melainkan isi kepala dan perilaku mereka. Orang Betawi juga memiliki sifat mudah bergaul dan terbuka. Hal ini dapat dilihat dari bentuk rumah yang cenderung satu lantai. Teras rumah merupakan tempat favorit mereka karena disanalah mereka dapat berkumpul dengan sanak saudara dan tetangga.

Pengaruh Melayu cukup kuat pada masyarakat penduduk pesisir dan tengah, sementara pengaruh kebudayaan Sunda cukup kental pada kebudayaan penduduk pinggiran dan udik. Namun, keempat subwilayah kebudayaan itu diikat oleh satu bahasa yang sama, yaitu bahasa Melayu.

Kebudayaan Betawi mendapat pengaruh dari Eropa, Cina, dan Arab, tetapi kebudayaan Betawi juga mempengaruhi ketiga kebudayaan tersebut ketika berkembang di Indonesia sehingga berpatokan pada asal nama sulit menentukan keabsahan dan keaslian suku bangsa Betawi. Sifat campur aduk dalam dialek Betawi adalah cerminan dari kebudayaan Betawi secara umum, yang merupakan hasil perkawinan berbagai macam kebudayaan, baik yang berasal dari daerah lain di Nusantara, maupun kebudayaan asing. Dengan keragaman yang luar biasa ini, artinya orang Betawi dapat menyerap kebudayaan asing yang diadaptasikan dengan lingkungan dan kebudayaan sendiri.

\section{SIMPULAN}

Sejak akhir abad yang lalu dan khususnya setelah kemerdekaan (1945), Jakarta dibanjiri imigran dari seluruh Indonesia sehingga orang Betawi - dalam arti apapun juga - tinggal sebagai minoritas. Pada tahun 1961, 'suku' Betawi mencakup kurang lebih 22,9\% dari antara 2,9 juta penduduk Jakarta pada waktu itu. Mereka semakin terdesak ke pinggiran, bahkan ramai-ramai digusur dan tergusur ke luar Jakarta. Walaupun sebetulnya, 'suku' Betawi tidaklah pernah tergusur atau digusur dari Jakarta. Karena proses asimilasi dari berbagai suku yang ada di Indonesia hingga kini terus berlangsung dan melalui proses panjang itu pulalah 'suku' Betawi hadir di bumi Nusantara. Dengan kekayaan budaya yang dimiliki oleh masyarakat Betawi, maka perlu adanya pelestarian terhadap kebudayaan ini, mengingat sifat masyarakatnya yang kurang perduli akan keberadaannya sendiri. 


\section{DAFTAR PUSTAKA}

Enskiklopedia Jakarta-Jilid 6. (2009). Jakarta: Lentera Abadi.

Heuken, A. J. (1999). Sumber-sumber asli sejarah Jakarta, jilid pertama, Jakarta: Yayasan Cipta Loka Caraka.

Profil kota Jakarta doeloe, kini, dan esok. (2009). Jilid ketujuh, Jakarta: Lentera Abadi.

Saidi, R. (2000). Siklus Betawi upacara dan adat istiadat, Jakarta: Lembaga kebudayaan Betawi.

Yunus, A. dkk. (1993). Arti dan fungsi upacara tradisional daur hidup pada masyarakat Betawi, Jakarta: Departemen Pendidikan dan Kebudayaan. 